\title{
Ciudadanía versus Ejecutivo: el uso de la consulta popular en Ecuador
}

\section{The people versus the Executive branch: the use of popular consultations in Ecuador.}

Sofía Velasco Ayala

Recepción: 31-05-2020

Aceptación: 30-07-2020

\begin{abstract}
La Constitución ecuatoriana de 2008 amplió la posibilidad de los ciudadanos para participar en temas de interés público a través de mecanismos de democracia directa. Sin embargo, argumentamos que uno de esos mecanismos, la consulta popular, ha presentado problemas para su activación desde la ciudadanía en comparación con el Ejecutivo.

Desarrollaremos nuestro argumento con un análisis de 34 iniciativas de consulta popular registradas entre 2010 y 2017, considerando tres variables: su patrocinador, cumplimiento de requisitos legales y si llegaron a la instancia de votación. Al evidenciar que muchas de las iniciativas versan sobre extracción de recursos naturales, enfatizamos en dos casos paradigmáticos al respecto. Con ello, planteamos una evaluación de la activación y uso de este mecanismo de democracia directa. Concluimos que la activación constante del mismo desde el Ejecutivo y la dificultad para hacerlo desde la ciudadanía, desvirtúa su propósito.

Palabras clave: consulta popular, mecanismos de democracia directa, extractivismo

The Ecuadorian Constitution emitted in 2008 widened the capacity of citizens to participate in topics of public concern by the use of mechanisms of direct democracy. However, we argue that one of these mechanisms, popular consultations, has been poorly activated successfully by the people in comparison to the Executive branch.

We develop our argument through an analysis of 34 initiatives of popular consultations registered between 2010 and 2017, considering three variables: who sponsors the initiative, legal requirement compliance and if they got to be voted. Since we evidence that many initiatives sponsored by the people include questions about the use and extraction of natural resources, we emphasize in two paradigmatic cases. Through this analysis, we plan to evaluate the activation and use of this mechanism of direct democracy. We conclude that its constant activation from the Executive branch and the difficulty to do so by the people, distorts its purpose.

Key Words: popular consultations, mechanisms of direct democracy, extractivism
\end{abstract}




\section{Introducción}

Tras las crisis democráticas y económicas al final del siglo XX, en América Latina se acumularon demandas ciudadanas que no habían

_ sido cubiertas por los Estados ni por el mercado. Nuevos programas de gobierno se presentaron para reavivar el interés en la democracia y fortalecer la institucionalidad, en respuesta al modelo neoliberal aplicado.

La región, o gran parte de ella, realizó un giro político a un momento post neoliberal, y con ello, la búsqueda de vías de fortalecimiento de las instituciones, con lo que nuevas formas de ejercicio democrático se presentaron como una posible solución. Una teoría democrática "que asume que la renovación de la representación es necesaria para reconstruir la calidad democrática” (Avritzer, 2012: 1) Desarrollar tal reconstrucción significó explorar nuevas formas de representación y mecanismos de participación en la esfera pública.

El gobierno de Rafael Correa en Ecuador asumió el poder en 2007 después de diez años de especial inestabilidad democrática, con un amplio plan de gobierno. Este fue presentado oficialmente a través del Plan Nacional de Desarrollo en 2007 y contenía un nuevo enfoque de desarrollo llamado Buen Vivir. La democratización y el fortalecimiento de la participación ciudadana fueron puntos importantes en el plan, así como el impulso de un nuevo modelo que procuraba la promoción de iniciativas que auspiciaran un "enfoque ambiental", que suponía ser transversal a los procesos manejados desde la administración pública; tales elementos eran coherentes con el mencionado enfoque de desarrollo. Una mezcla de ambos puntos, la democratización y el enfoque ambiental, fueron reflejados en el décimo objetivo del Plan Nacional de Desarrollo 2007: "Garantizar el acceso a la participación pública y política"; y, en especial, a una de las políticas enmarcadas en este objetivo, que rezaba: "Promover la organización colectiva y autónoma de la sociedad civil", siendo una estrategia de dicha política el "promover la participación social respecto a decisiones que pudieran afectar el medio ambiente".

En 2008 se emite una nueva Constitución. Este texto era coherente con el Plan Nacional de Desarrollo 2007 y presentaba un amplio catálogo de 
derechos que incluía derechos de participación, lo cual significaba un importante paso adelante respecto al fortalecimiento de la participación ciudadana, en comparación con la Constitución de 1998 (Morales, 2008). El artículo 95 incluyó el derecho de la ciudadanía a participar en cualquier asunto de interés público a través de mecanismos de democracia directa, representativa y comunitaria.

Los mecanismos de democracia directa (en adelante MDD) en Ecuador son la iniciativa legislativa ciudadana, la silla vacía y la consulta popular. Este último puede ser activado por la presidencia de la República, autoridades de gobiernos seccionales y ciudadanos ecuatorianos residentes dentro y fuera del territorio ecuatoriano. Las propuestas iniciadas por la ciudadanía pueden incluir temas de interés nacional, las mismas que requieren el $5 \%$ de apoyo del electorado a través de firmas; y temas de interés local o subnacional, requieren $10 \%$ de apoyo del electorado. Estas iniciativas no se pueden referir a tributos, gasto público ni organización político administrativa del país. Las preguntas y considerandos deben contar con el dictamen de constitucionalidad otorgado por la Corte Constitucional. Por otro lado, las propuestas iniciadas desde el Ejecutivo solamente requieren este dictamen. Por lo tanto, desde una lectura al diseño institucional de la consulta, según quien la activa, esta es más accesible para el Ejecutivo.

A pesar de la aparente accesibilidad general a las consultas populares, la gran mayoría de iniciativas presentadas no llegan a ser consultas populares o a la instancia de votación. Los MDD en Ecuador se presentan como herramientas para democratizar el acceso de los ciudadanos a asuntos públicos. De acuerdo a Welp (2016), en sistemas presidencialistas -como sería el ecuatoriano- el uso de consultas populares desde la ciudadanía, le otorgan a la misma mayor poder de intervención. Su uso desde el Ejecutivo podría, por un lado, crear un desequilibrio entre funciones o, por otro, legitimar la toma de decisiones a través del voto popular. Lissidini (2015) advierte sobre el uso político que podrían tener los mecanismos de democracia directa activados desde el Ejecutivo, ya que podrían tener fines legitimantes. A la vez, Altman expone peligros de los MDDs cuando "piezas clave del andamiaje institucional no gozan de buena salud" (Altman, 2010: 29). 
Si de un total de 34 iniciativas analizadas, muy pocas llegan a la instancia de ser votadas, con base en lo expuesto nos podríamos preguntar ¿Qué iniciativas de consulta popular llegan efectivamente a ser votadas?

Responderemos la pregunta respecto a las iniciativas de consulta popular ingresadas al Consejo Nacional Electoral entre 2010 y 2017. Los datos fueron obtenidos de la Secretaría General del CNE. Seleccionamos este rango temporal ya que 2010 fue el año en que los cuerpos legales que regulaban la consulta popular se terminaron de emitir, y en 2017 la última consulta de carácter nacional votada fue propuesta, siendo votada en febrero de 2018, acarreando repercusiones respecto a una iniciativa previamente ingresada. Cada iniciativa será analizada a través de categorías respecto a nuestro argumento e hipótesis alternativas. Recalcamos que el análisis versa sobre si las iniciativas llegan o no a votarse.

Como antecedente a este análisis, Franklin Ramírez (2014) realizó un estudio de los MDD en Ecuador posconstitucional, que incluyó las iniciativas de consulta popular. Utilizó criterios similares al que presentaremos y su análisis incluyó las iniciativas presentadas entre 2010 y 2012. Concluye que, a pesar de que los MDD son más accesibles desde la emisión de la Constitución de 2008, más iniciativas fueron presentadas antes de 2011, siendo su única explicación que en 2011 se presentaron nuevos requisitos legales, lo cual dificultó el acceso a estos mecanismos para la posteridad. Nosotros consideramos que a pesar de que su argumento pudo ser válido, que una iniciativa llegue a ser votada está más marcado por quién la propone. Esta variable podría ser más relevante si solamente llegan a votarse las propuestas por el presidente, a pesar de incumplir requisitos legales o mantener un doble estándar en la verificación de cumplimiento.

Una hipótesis alternativa puede referirse a los temas consultados. Podría haber temas que estén comúnmente incluidos en iniciativas rechazadas.

Otra hipótesis alternativa, y la más obvia considerando que Ecuador es un estado de derechos según la Constitución, se referiría a que las iniciativas de consulta popular no llegan a votarse debido a que no cumplen requisitos legales. 
Presentaremos una visión general respecto al argumento, mostrando cuáles serían sus directas implicaciones, así como las explicaciones alternativas. Luego, incluiremos algunos conceptos clave y requisitos legales que deben cumplir las iniciativas de consulta popular para llegar a votarse; con ello, analizaremos nuestra muestra contrastándola con el argumento presentado.

\section{Argumento}

De acuerdo al primer artículo de la Constitución de Ecuador, el país es una democracia, "un Estado de derechos y justicia". Que una iniciativa llegue a ser votada debería corresponder al cumplimiento de requisitos legales. Nosotros argumentaremos que este "deber ser" no se aplica a nuestra muestra. Las iniciativas de consulta popular llegan a votarse dependiendo de quién las auspicia.

Al mismo tiempo, debemos tener en cuenta que los requisitos legales varían dependiendo de quién auspicia la iniciativa; de esa manera nuestro argumento se fortalece ya que el éxito de la iniciativa puede ser más fácil de alcanzar para el presidente, que para la ciudadanía.

De ser así, estaríamos en condiciones de plantear la necesidad de repensar los requisitos que se proponen a la ciudadanía para llevar adelante una consulta y su comparación con los requisitos planteados al poder ejecutivo.

Nuestro argumento podría llevarnos a preguntar si las consultas populares como mecanismos de democracia directa usadas por los presidentes tienen como objetivo poner un rostro democrático a decisiones controversiales respecto a políticas públicas; para introducir asuntos difíciles de manejar a través de la vía legislativa dentro de la agenda pública; o, como medidores de popularidad.

\section{Explicaciones alternativas}

La principal razón de que las iniciativas de consulta popular sean exitosas -en el sentido antes referido, es decir, que lleguen a la instancia de consulta popular- podría referirse al cumplimiento de requisitos legales. Esto ocurriría en un perfecto caso de Estado de Derecho, con andamiaje institucional correspondiente. Todos los requisitos a cumplir deberían estar claramente 
especificados para que así, los mecanismos estén al alcance de todos los interesados, y se desechen en caso de claro incumplimiento.

El fracaso de una iniciativa de consulta popular podría deberse a una defectuosa exposición de requisitos legales o a una mala socialización de los mismos. Esto nos conduciría a ver que el acceso a los MDD no se encuentra totalmente abierto para la universalidad y diversidad de ciudadanos. Por lo tanto, no estarían cumpliendo su inicial cometido: democratizar el acceso de la ciudadanía a asuntos públicos.

A la vez, esto podría significar que no se estaría ejerciendo la ciudadanía de forma activa, ya que los ciudadanos no se encontrarían plenamente informados, o no habría una cultura política de participación que se pudiera fortalecer. La disponibilidad de los MDD no iría de la mano con la promoción de la participación ciudadana.

Otra hipótesis alternativa se refiere a que muchos de los asuntos públicos solo están reservados para ser consultados por el presidente o la función legislativa. En estos casos, podría haber un uso repetido de este mecanismo respecto a temas exclusivos para estos actores, lo cual ampliaría la activación desde las autoridades.

También se podría argumentar que algunos temas consultados son accesibles a través consultas populares solamente en algunos momentos. Por ejemplo, existen temas que son presentados en un momento y demoran mucho tiempo en alcanzar éxito, o son rechazados y presentados nuevamente para alcanzar éxito en otro momento. Eso podría significar que el acceso a MDD como la consulta popular es conveniente en ciertos tiempos, pero en otros no, lo que podría tornar a los resultados de las consultas en medidores de opinión pública solo cuando puedan ser beneficiosas a la agenda de política pública o para crear ventanas de oportunidad para políticas relacionadas o temas presentados junto a otros de mayor aceptación popular.

Nuestras hipótesis alternativas se apoyan en las explicaciones de Lissidini, Welp y Zovatto, quienes señalan que:

En definitiva, los usos y efectos de los mecanismos de democracia 
participativa y democracia directa están condicionados por el diseño legal, quienes pueden iniciarla (Poder Ejecutivo o ciudadanos, gobiernos locales o nacionales), por el grado de dificultad para ponerlas en marcha, reglas sobre el debate y la publicidad; los legados políticos (sistema de partidos, autonomía de la sociedad civil, entre otros), y por cómo se imbrican con el juego político en un sentido amplio (reforzando o modificando la dinámica política preexistente). (Lissidini, Welp, \& Zovatto, 2014: 9)

En resumen, otros argumentos respecto al éxito de las iniciativas de consulta popular incluyen: cumplimiento de requisitos legales, temas de consulta y momento político.

\section{Diseño de investigación}

\section{a. Algunas definiciones a tener en cuenta}

Los mecanismos de democracia directa son elementos de activación política y de ejercicio pleno de la participación ciudadana respecto a la política. Zovatto los define como

modalidades de participación política en las que, a través del ejercicio del voto directo y universal, es decir las consultas populares (en sus diversas formas jurídicas: plebiscito, referéndum y revocatoria de mandato), los ciudadanos votan a favor o en contra de una propuesta (Zovatto, 2014: 14).

Las consultas populares son deliberaciones públicas y directas que el electorado realiza sobre temas específicos. Las preguntas propuestas para las consultas populares se realizan para que el gobierno o el poder legislativo tengan un insumo vinculante para ser aplicado o desarrollado a través de política pública, en el caso ecuatoriano.

Este MDD no debe ser confundido con la consulta previa, paso obligatorio en proyectos de explotación de recursos naturales que pueden afectar territorios donde viven pueblos originarios, teniendo que ser llevada a cabo por el Estado en cumplimiento de la Convención 169 de la OIT. 


\section{b. Marco legal y requisitos a cumplir}

El marco legal de las consultas populares en Ecuador incluye a la Constitución con el artículo 104; la Ley Orgánica de Participación Ciudadana, con los artículos 19, 20, 21, 22, 23 y 24; la Ley Orgánica de Elecciones o Código de la Democracia, con los artículos 195, 196, 197 y 198; Ley Orgánica de Garantías Jurisdiccionales y Control Constitucional, con los artículos $102,103,104,105$ y 127; y el Reglamento para el Ejercicio de la Democracia Directa, con los artículos 4, 5, 6, 7, 8, 9, 10, 11 y 12.

El marco legal señala los requisitos que las iniciativas de consulta popular deben cumplir para llegar a votarse. De acuerdo al mismo, las iniciativas pueden ser auspiciadas o activadas por el presidente/a del Ecuador, la Asamblea Nacional, autoridades de gobiernos locales y ciudadanos ecuatorianos residentes dentro o fuera de territorio ecuatoriano.

Para las iniciativas activadas por el presidente, los temas son ilimitados y el único requisito es la aprobación por la Corte Constitucional, donde sus miembros deben controlar que tanto las preguntas como sus considerandos no sean contrarios a la Constitución. Con la aprobación de la Corte Constitucional, la iniciativa retorna al CNE para proceder a llamar a elecciones.

Las iniciativas de autoridades de gobiernos locales deben ser apoyadas por las tres cuartas partes del consejo de gobierno local. Deben tener aprobación de la Corte Constitucional y los asuntos sobre los que pueden tratar las preguntas deben limitarse a temas respecto a su jurisdicción, a excepción de asuntos tributarios.

La Asamblea Nacional solo puede activar consultas populares para que el pueblo se pronuncie respecto a una petición realizada por el Ejecutivo, en relación a declaración de interés nacional de explotación de recursos naturales no renovables en zonas protegidas o declaradas intangibles. Esta activación es opcional, ya que queda a discreción de la Asamblea llamar a consulta para realizar esta declaración.

Los ciudadanos pueden presentar iniciativas de consulta popular y requieren aprobación de la Corte Constitucional. Después de tal aprobación, el 
CNE debe entregar los formularios de recolección de firmas, misma que se debe dar en 80 días. Si el tema de consulta es local, requiere un 10\% de apoyo del electorado correspondiente. Si es un tema nacional, $5 \%$ de apoyo del electorado es necesario. Dicho apoyo se denomina legitimidad democrática. El CNE debe validar las firmas, y si dicho requisito es completado, las elecciones se deben llevar a cabo. Los ciudadanos no pueden llamar a consultas populares respecto a temas tributarios o de organización político administrativa.

El 25 de septiembre de 2013, la Corte Constitucional emitió una sentencia erga omnes que dictaba que el momento de aprobación de la Corte Constitucional sigue al de verificación de legitimidad democrática (Corte Constitucional del Ecuador, 2013). Esto significa que una vez que el CNE confirma la legitimidad democrática, la Corte Constitucional debe dar su dictamen de constitucionalidad ${ }^{1}$. Cabe recalcar que, de acuerdo a la LOGJCC, si no hay un dictamen de la Corte Constitucional en veinte días desde el ingreso de la iniciativa en este órgano, el mismo se entiende favorable.

Otra activación de consulta popular puede darse para instalar una asamblea constituyente, para elaborar una nueva Constitución. La iniciativa puede ser activada por el presidente de la República, dos tercios de la Asamblea Nacional o el $12 \%$ del electorado.

Para nuestro análisis, ubicaremos 34 iniciativas de consulta popular que componen nuestra muestra en un cuadro en que conste cuándo inició el proceso, qué tema comprendía, si contó con la aprobación de la Corte Constitucional; si fue de carácter nacional o local (y si fue local, qué jurisdicción tenía), y cuál fue la resolución del CNE.

1 El 26 de abril de 2019 la nueva Corte Constitucional a través del dictamen 1-19-CP/19 señala que el control constitucional podrá realizarse sin requerir el respaldo de la recolección de firmas. 


\section{c. Análisis de las iniciativas de consulta popular}

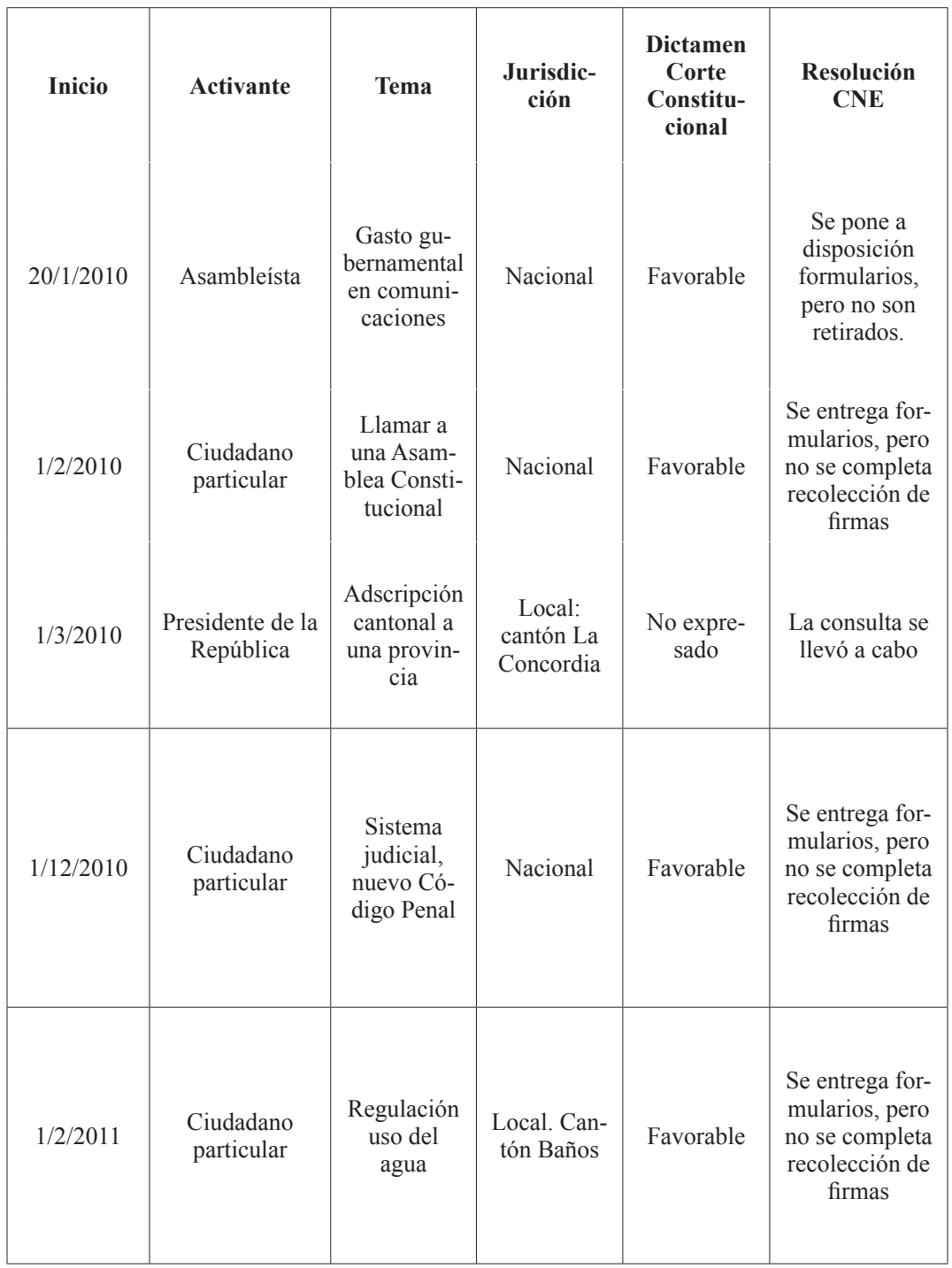




\begin{tabular}{|c|c|c|c|c|c|}
\hline $1 / 2 / 2011$ & $\begin{array}{l}\text { Presidente de la } \\
\text { República }\end{array}$ & $\begin{array}{c}\text { Prisión pre- } \\
\text { ventiva, de- } \\
\text { recho penal; } \\
\text { prohibicio- } \\
\text { nes de po- } \\
\text { seer medios } \\
\text { de comu- } \\
\text { nicación a } \\
\text { banqueros; } \\
\text { cambios en } \\
\text { la función } \\
\text { judicial; } \\
\text { prohibir } \\
\text { espectá- } \\
\text { culos que } \\
\text { incluyan la } \\
\text { muerte de } \\
\text { animales en } \\
\text { cantones; } \\
\text { prohibición } \\
\text { de juegos } \\
\text { de azar; } \\
\text { crear la Ley } \\
\text { Orgánica de } \\
\text { Comunica- } \\
\text { ción }\end{array}$ & Nacional & $\begin{array}{c}11 \text { pregun- } \\
\text { tas: } 10 \text { con } \\
\text { dictamen } \\
\text { favorable y } \\
1 \text { no favo- } \\
\text { rable }\end{array}$ & $\begin{array}{c}\text { Se llevó a cabo } \\
\text { la consulta con } \\
10 \text { preguntas }\end{array}$ \\
\hline Inicio & Activante & Tema & $\begin{array}{l}\text { Jurisdic- } \\
\text { ción }\end{array}$ & $\begin{array}{l}\text { Dictamen } \\
\text { Corte } \\
\text { Constitu- } \\
\text { cional }\end{array}$ & $\begin{array}{l}\text { Resolución } \\
\text { CNE }\end{array}$ \\
\hline $1 / 10 / 2011$ & $\begin{array}{l}\text { Ciudadano } \\
\text { particular }\end{array}$ & $\begin{array}{c}\text { Regulación } \\
\text { en materia } \\
\text { de niñez, } \\
\text { familia y } \\
\text { adolescen- } \\
\text { cia }\end{array}$ & Nacional & Favorable & $\begin{array}{l}\text { Se pone a } \\
\text { disposición } \\
\text { formularios, } \\
\text { pero no son } \\
\text { retirados. }\end{array}$ \\
\hline
\end{tabular}




\begin{tabular}{|c|c|c|c|c|c|}
\hline $\begin{array}{l}\text { 1/3/2012 } \\
\text { Formula- } \\
\text { rios: } 2015 \\
\text { Votación: } \\
2019\end{array}$ & $\begin{array}{c}\text { Integrantes de } \\
\text { la unión de } \\
\text { sistemas co- } \\
\text { munitarios de } \\
\text { agua del cantón } \\
\text { Girón, de la } \\
\text { provincia del } \\
\text { Azuay, filial de } \\
\text { la FOA-ECU- } \\
\text { RUNARI-CO- } \\
\text { NAIE }\end{array}$ & $\begin{array}{l}\text { Explotación } \\
\text { minera en } \\
\text { el sistema } \\
\text { hidrológico } \\
\text { de Quim- } \\
\text { sacocha }\end{array}$ & $\begin{array}{l}\text { Local. Can- } \\
\text { tón Girón }\end{array}$ & $\begin{array}{l}\text { No expre- } \\
\text { sado }\end{array}$ & $\begin{array}{l}\text { La consulta se } \\
\text { lleva a cabo } \\
\text { luego de } 7 \text { años }\end{array}$ \\
\hline $25 / 3 / 2013$ & $\begin{array}{l}\text { Ciudadano } \\
\text { particular }\end{array}$ & $\begin{array}{l}\text { Regulación } \\
\text { de manu- } \\
\text { tención } \\
\text { infantil }\end{array}$ & Nacional & Favorable & $\begin{array}{l}\text { Se entrega for- } \\
\text { mularios, pero } \\
\text { no se completa } \\
\text { recolección de } \\
\text { firmas }\end{array}$ \\
\hline $22 / 8 / 2013$ & $\begin{array}{l}\text { Ciudadano } \\
\text { particular }\end{array}$ & $\begin{array}{c}\text { Extracción } \\
\text { de petró- } \\
\text { leo en el } \\
\text { bloque ITT } \\
\text { del Parque } \\
\text { Nacional } \\
\text { Yasuní }\end{array}$ & Nacional & $\begin{array}{l}\text { No expre- } \\
\text { sado }\end{array}$ & $\begin{array}{l}\text { Recolección de } \\
\text { firmas comple- } \\
\text { ta, pero en su } \\
\text { gran mayoría } \\
\text { se declaran } \\
\text { inválidas. }\end{array}$ \\
\hline $27 / 9 / 2013$ & $\begin{array}{l}\text { Ciudadano } \\
\text { particular }\end{array}$ & $\begin{array}{c}\text { Explotación } \\
\text { petrolera en } \\
\text { el bloque } \\
\text { ITT del } \\
\text { Parque } \\
\text { Nacional } \\
\text { Yasuní }\end{array}$ & Nacional & $\begin{array}{l}\text { Pide com- } \\
\text { pletar requi- } \\
\text { sitos }\end{array}$ & $\begin{array}{l}\text { Sin pronuncia- } \\
\text { miento }\end{array}$ \\
\hline
\end{tabular}




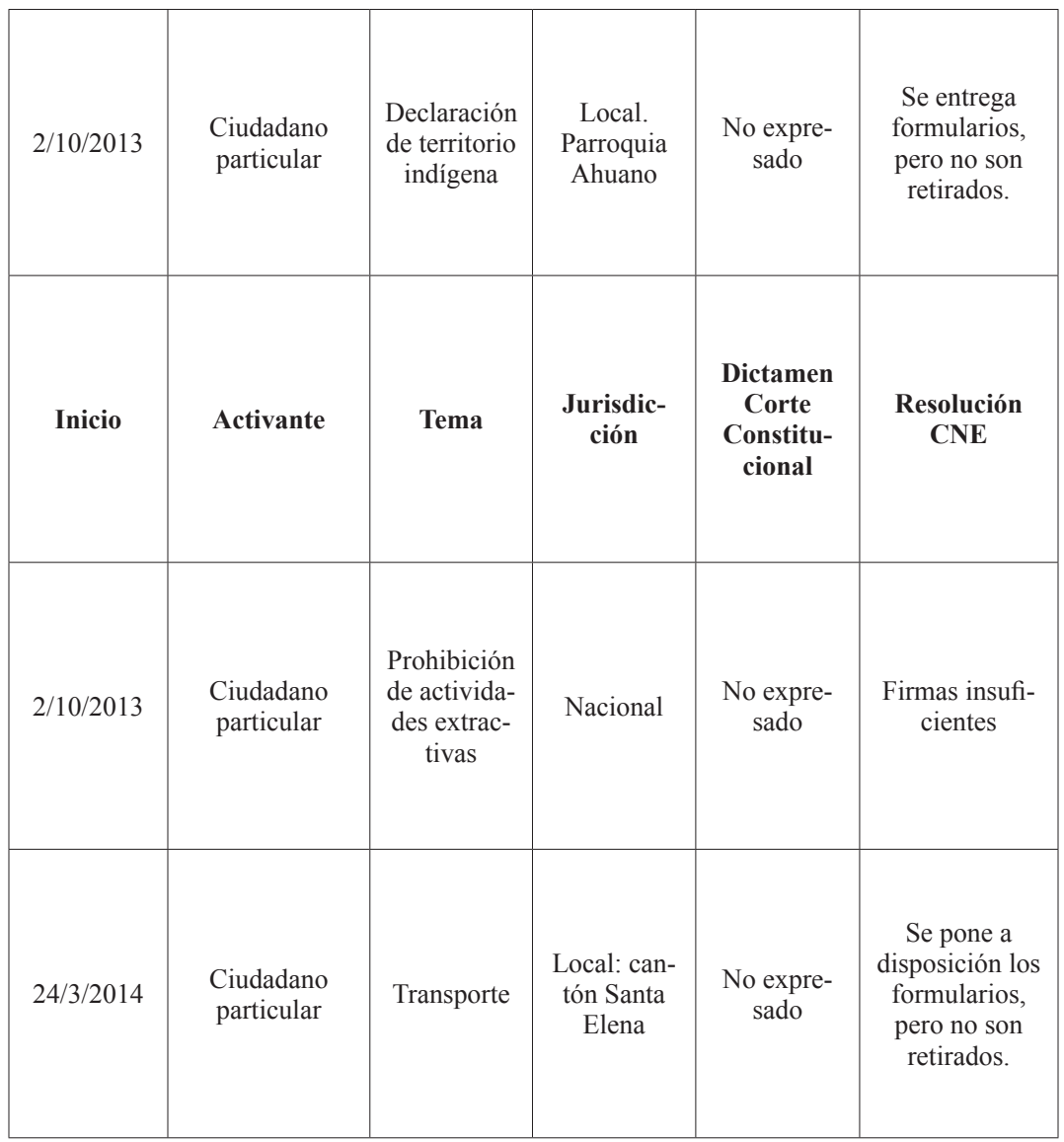




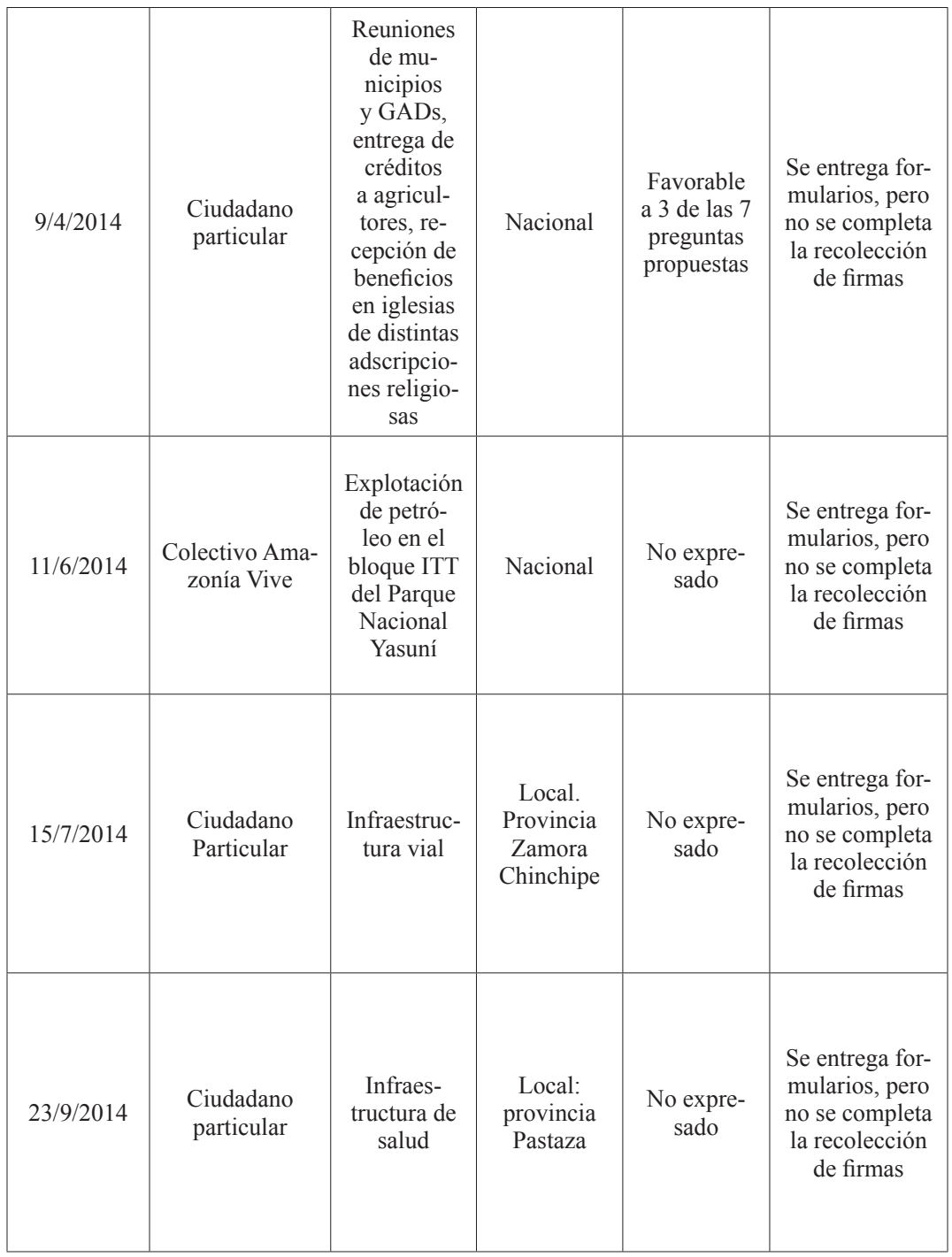




\begin{tabular}{|c|c|c|c|c|c|}
\hline Inicio & Activante & Tema & $\begin{array}{l}\text { Jurisdic- } \\
\text { ción }\end{array}$ & $\begin{array}{l}\text { Dictamen } \\
\text { Corte } \\
\text { Constitu- } \\
\text { cional }\end{array}$ & $\begin{array}{l}\text { Resolución } \\
\text { CNE }\end{array}$ \\
\hline $5 / 3 / 2015$ & $\begin{array}{l}\text { Ciudadano } \\
\text { particular }\end{array}$ & $\begin{array}{l}\text { Transporte } \\
\text { público }\end{array}$ & $\begin{array}{l}\text { Local: } \\
\text { ciudad } \\
\text { Guayaquil }\end{array}$ & Favorable & $\begin{array}{l}\text { Se completa el } \\
\text { proceso, pero } \\
\text { auspiciantes } \\
\text { deciden no } \\
\text { llevar a cabo la } \\
\text { consulta }\end{array}$ \\
\hline $20 / 1 / 2016$ & $\begin{array}{l}\text { Presidente de la } \\
\text { República }\end{array}$ & $\begin{array}{l}\text { Límites } \\
\text { territoriales }\end{array}$ & $\begin{array}{l}\text { Local: } \\
\text { provincias } \\
\text { Esmeraldas } \\
\text { e Imbabura }\end{array}$ & Favorable & $\begin{array}{l}\text { La consulta se } \\
\text { llevó a cabo }\end{array}$ \\
\hline $29 / 2 / 2016$ & $\begin{array}{l}\text { Ciudadano } \\
\text { particular }\end{array}$ & Territorio & $\begin{array}{l}\text { Local: } \\
\text { provincia } \\
\text { Orellana }\end{array}$ & $\begin{array}{l}\text { No expre- } \\
\text { sado }\end{array}$ & $\begin{array}{c}\text { CNE devuelve } \\
\text { el proceso al } \\
\text { auspiciante }\end{array}$ \\
\hline $16 / 3 / 2016$ & $\begin{array}{l}\text { Ciudadanos } \\
\text { particulares }\end{array}$ & $\begin{array}{l}\text { Transporte } \\
\text { público }\end{array}$ & $\begin{array}{l}\text { Local: pro- } \\
\text { vincia Santa } \\
\text { Elena }\end{array}$ & $\begin{array}{l}\text { No expre- } \\
\text { sado }\end{array}$ & $\begin{array}{c}\text { Se presentan } \\
3 \text { preguntas, } \\
\text { pero el CNE } \\
\text { da formularios } \\
\text { para una de } \\
\text { ellas. Nunca } \\
\text { se presenta las } \\
\text { firmas }\end{array}$ \\
\hline & & & & & \\
\hline
\end{tabular}


Sofía Velasco Ayala

\begin{tabular}{|c|c|c|c|c|c|}
\hline $28 / 3 / 2016$ & $\begin{array}{l}\text { Ciudadano } \\
\text { particular }\end{array}$ & $\begin{array}{l}\text { Autoridades } \\
\text { de gobierno } \\
\text { local }\end{array}$ & $\begin{array}{l}\text { Local: ciu- } \\
\text { dad Muisne }\end{array}$ & $\begin{array}{l}\text { No expre- } \\
\text { sado }\end{array}$ & $\begin{array}{c}\text { CNE devuelve } \\
\text { el proceso a } \\
\text { sus auspician- } \\
\text { tes }\end{array}$ \\
\hline $24 / 05 / 2016$ & $\begin{array}{l}\text { Ciudadano } \\
\text { particular }\end{array}$ & $\begin{array}{l}\text { Referéndum } \\
\text { reelección } \\
\text { indefinida }\end{array}$ & Nacional & $\begin{array}{l}\text { No expre- } \\
\text { sado }\end{array}$ & $\begin{array}{l}\text { Se entrega for- } \\
\text { mularios, pero } \\
\text { no se completa } \\
\text { recolección de } \\
\text { firmas }\end{array}$ \\
\hline $30 / 8 / 2016$ & $\begin{array}{l}\text { Ciudadano } \\
\text { particular }\end{array}$ & $\begin{array}{l}\text { Delitos en } \\
\text { la admi- } \\
\text { nistración } \\
\text { pública }\end{array}$ & Nacional & $\begin{array}{l}\text { No expre- } \\
\text { sado }\end{array}$ & $\begin{array}{l}\text { Iniciativa de- } \\
\text { clarada incons- } \\
\text { titucional por } \\
\text { el CNE }\end{array}$ \\
\hline $14 / 11 / 2016$ & $\begin{array}{l}\text { Ciudadano } \\
\text { particular }\end{array}$ & $\begin{array}{l}\text { Transporte } \\
\text { público }\end{array}$ & $\begin{array}{l}\text { Local: } \\
\text { provincia } \\
\text { Guayas }\end{array}$ & $\begin{array}{l}\text { No expre- } \\
\text { sado }\end{array}$ & $\begin{array}{c}\text { Iniciativa } \\
\text { contraria al Re- } \\
\text { glamento para } \\
\text { el ejercicio de } \\
\text { la democracia } \\
\text { directa }\end{array}$ \\
\hline Inicio & Activante & Tema & $\begin{array}{l}\text { Jurisdic- } \\
\text { ción }\end{array}$ & $\begin{array}{l}\text { Dictamen } \\
\text { Corte } \\
\text { Constitu- } \\
\text { cional }\end{array}$ & $\begin{array}{l}\text { Resolución } \\
\text { CNE }\end{array}$ \\
\hline $7 / 12 / 2016$ & $\begin{array}{l}\text { Presidente de la } \\
\text { República }\end{array}$ & $\begin{array}{l}\text { Prohibición } \\
\text { a funciona- } \\
\text { rios públi- } \\
\text { cos }\end{array}$ & Nacional & Favorable & $\begin{array}{l}\text { La consulta se } \\
\text { llevó a cabo }\end{array}$ \\
\hline $24 / 04 / 2017$ & $\begin{array}{l}\text { Ciudadano } \\
\text { particular }\end{array}$ & $\begin{array}{l}\text { Instalación } \\
\text { de asamblea } \\
\text { constitu- } \\
\text { yente }\end{array}$ & Nacional & $\begin{array}{l}\text { No expre- } \\
\text { sado }\end{array}$ & $\begin{array}{c}\text { Se devuelve } \\
\text { proceso a } \\
\text { activantes }\end{array}$ \\
\hline
\end{tabular}




\begin{tabular}{|c|c|c|c|c|c|}
\hline $18 / 7 / 2017$ & $\begin{array}{l}\text { Ciudadano } \\
\text { particular }\end{array}$ & $\begin{array}{l}\text { Funciones } \\
\text { de los } \\
\text { asambleís- } \\
\text { tas }\end{array}$ & Nacional & $\begin{array}{l}\text { No expre- } \\
\text { sado }\end{array}$ & $\begin{array}{l}\text { No se admite } \\
\text { la iniciativa }\end{array}$ \\
\hline $14 / 8 / 2017$ & $\begin{array}{l}\text { Ciudadano } \\
\text { particular }\end{array}$ & $\begin{array}{l}\text { Cambios } \\
\text { al Código } \\
\text { Integral } \\
\text { Penal, } \\
\text { eliminación } \\
\text { de insti- } \\
\text { tuciones, re- } \\
\text { moción de } \\
\text { autoridades, } \\
\text { cambios } \\
\text { constitu- } \\
\text { cionales, } \\
\text { eliminación } \\
\text { de la LOC }\end{array}$ & Nacional & $\begin{array}{l}\text { No expre- } \\
\text { sado }\end{array}$ & $\begin{array}{c}\text { No se admite } \\
\text { por inconstitu- } \\
\text { cional }\end{array}$ \\
\hline $09 / 11 / 2017$ & $\begin{array}{l}\text { Ciudadano } \\
\text { particular }\end{array}$ & $\begin{array}{l}\text { Refe- } \\
\text { réndum, } \\
\text { cambios a } \\
\text { la Cons- } \\
\text { titución, } \\
\text { nepotismo } \\
\text { en el sector } \\
\text { público }\end{array}$ & Nacional & $\begin{array}{l}\text { No expre- } \\
\text { sado }\end{array}$ & $\begin{array}{l}\text { Se entrega for- } \\
\text { mularios, pero } \\
\text { no se completa } \\
\text { la recolección } \\
\text { de firmas }\end{array}$ \\
\hline $10 / 11 / 2017$ & $\begin{array}{l}\text { Ciudadanos } \\
\text { particulares }\end{array}$ & $\begin{array}{c}\text { Autonomía } \\
\text { y descen- } \\
\text { tralización, } \\
\text { turismo } \\
\text { sustentable, } \\
\text { reformas } \\
\text { educativas, } \\
\text { migración. }\end{array}$ & Nacional & $\begin{array}{l}\text { No expre- } \\
\text { sado }\end{array}$ & $\begin{array}{l}\text { No se admite } \\
\text { la iniciativa }\end{array}$ \\
\hline
\end{tabular}




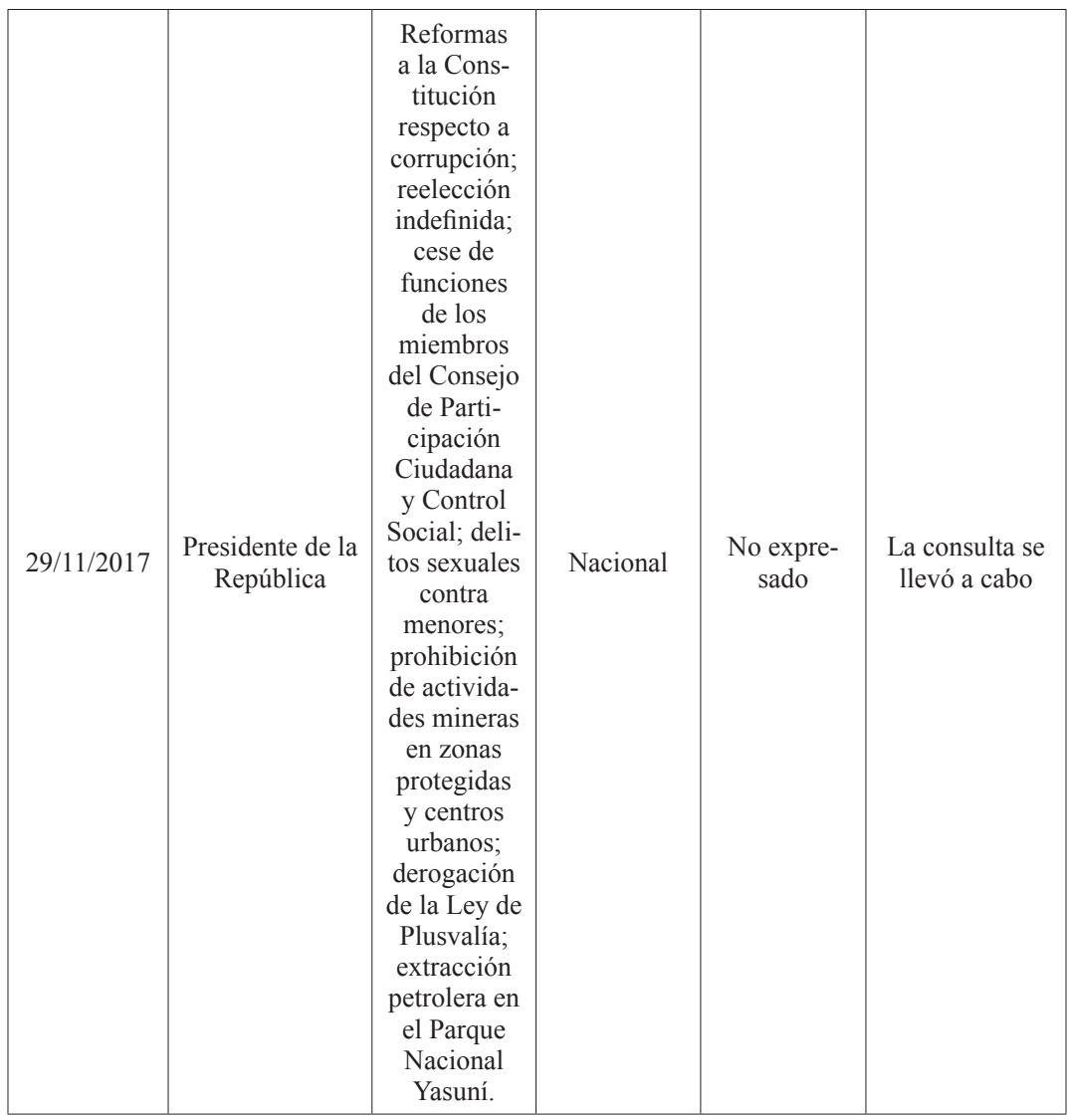

Tabla 1: Análisis de iniciativas de consultas populares

Fuente: Elaboración propia con datos de Secretaría General del CNE

\section{Primeros resultados e hipótesis alternativas}

Hemos presentado 34 iniciativas de consulta popular en nuestra muestra. De éstas, 8 llegaron a votarse; sin embargo, una no se vota ya que los activantes desisten de hacerlo. 


\begin{tabular}{|c|c|c|c|}
\hline Fecha & Activante/Auspiciante & Tema & $\begin{array}{l}\text { Dictamen de la } \\
\text { Corte Consti- } \\
\text { tucional }\end{array}$ \\
\hline $01 / 03 / 10$ & $\begin{array}{l}\text { Presidente de la República } \\
\text { (Rafael Correa) }\end{array}$ & $\begin{array}{l}\text { Adscripción de un } \\
\text { cantón a una provincia }\end{array}$ & No expresado \\
\hline $21 / 02 / 2011$ & $\begin{array}{l}\text { Presidente de la República } \\
\text { (Rafael Correa) }\end{array}$ & $\begin{array}{l}\text { Prisión preventiva, } \\
\text { derecho penal; pro- } \\
\text { hibiciones de poseer } \\
\text { medios de comuni- } \\
\text { cación a banqueros; } \\
\text { cambios en la función } \\
\text { judicial; prohibir } \\
\text { en los cantones } \\
\text { espectáculos que } \\
\text { incluyan la muerte de } \\
\text { animales; prohibición } \\
\text { de juegos de azar; } \\
\text { crear la Ley Orgánica } \\
\text { de Comunicación }\end{array}$ & $\begin{array}{c}\text { Favorable en } 10 \text { de } \\
\text { las } 11 \text { preguntas } \\
\text { propuestas }\end{array}$ \\
\hline 01/06/2011 & $\begin{array}{c}\text { Unión de ciudadanos: comité } \\
\text { pro-mejoras }\end{array}$ & $\begin{array}{l}\text { Adscripción de tierras } \\
\text { comunitarias en la } \\
\text { parroquia de Caspi- } \\
\text { gasí del Carmen }\end{array}$ & Favorable \\
\hline $\begin{array}{c}\text { 1/3/2012 } \\
\text { Formularios: } \\
2015 \\
\text { Votación: } \\
2019\end{array}$ & $\begin{array}{l}\text { Integrantes de la unión de } \\
\text { sistemas comunitarios de } \\
\text { agua del cantón Girón, de } \\
\text { la provincia del Azuay, } \\
\text { filial de la FOA-ECUA- } \\
\text { RUNARI-CONAIE }\end{array}$ & $\begin{array}{l}\text { Explotación minera en } \\
\text { el sistema hidrológico } \\
\text { de Quimsacocha }\end{array}$ & No expresado \\
\hline $20 / 01 / 2016$ & $\begin{array}{l}\text { Presidente de la República } \\
\text { (Rafael Correa) }\end{array}$ & Límites territoriales & Favorable \\
\hline $5 / 03 / 2015$ & $\begin{array}{l}\text { Ciudadano particular (de- } \\
\text { siste) }\end{array}$ & Transporte público & Favorable \\
\hline $07 / 12 / 2016$ & $\begin{array}{l}\text { Presidente de la República } \\
\text { (Rafael Correa) }\end{array}$ & $\begin{array}{l}\text { Prohibiciones a em- } \\
\text { pleados públicos }\end{array}$ & Favorable \\
\hline
\end{tabular}




\begin{tabular}{|c|c|c|c|}
\hline $29 / 11 / 2017$ & $\begin{array}{l}\text { Presidente de la República } \\
\text { (Lenín Moreno) }\end{array}$ & $\begin{array}{l}\text { Reformas a la Cons- } \\
\text { titución respecto a } \\
\text { corrupción; reelección } \\
\text { indefinida; cese de } \\
\text { funciones de miem- } \\
\text { bros del Consejo de } \\
\text { Participación Ciuda- } \\
\text { dana y Control Social; } \\
\text { delitos sexuales contra } \\
\text { menores; prohibición } \\
\text { de actividades mine- } \\
\text { ras en zonas protegi- } \\
\text { das y centros urbanos; } \\
\text { derogación de la } \\
\text { Ley de Plusvalía; } \\
\text { extracción petrolera } \\
\text { en el Parque Nacional } \\
\text { Yasuní. }\end{array}$ & No expresado \\
\hline
\end{tabular}

Tabla 2: Consultas populares que llegaron a instancia de votación

Fuente: Elaboración propia con datos Secretaría General del CNE

\section{a. Auspiciantes o activantes de las iniciativas que llegaron a instancia de votación}

Nuestro argumento señalaba que la iniciativa de consulta popular llegaría a votarse dependiendo de quién la auspiciaba. De las iniciativas que llegaron a esta instancia, 5 fueron propuestas por el presidente de la República, mientras que 3 fueron propuestas por ciudadanos. Dos de las iniciativas presentadas por el presidente no contaron con el necesario dictamen de la Corte Constitucional, pero teniendo en cuenta el plazo de 20 días para otorgar el mismo, se consultaron. Sin embargo, el mismo plazo no fue considerado para la consulta sobre minería en Quimsacocha de manera oportuna, por lo que no existe una aplicación uniforme de la ley. Todas las iniciativas presentadas por el presidente se votaron.

Las tres iniciativas presentadas por ciudadanos tuvieron una aplicación local y cumplieron todos los requisitos legales correspondientes: dos de ellas con dictamen favorable de la Corte Constitucional y una sin dictamen dentro de los 20 días de plazo. 


\section{b. Temas de las consultas votadas}

En una de nuestras hipótesis alternativas señalamos que las iniciativas que llegan a votarse pueden depender del tema al que se refieren. En nuestra muestra: tres de ellas se referían a territorio, una a transporte público, una a minería, una a prohibiciones a empleados públicos y dos, presentadas por el presidente, incluían varios asuntos y combinaban referéndum con consulta popular. La última iniciativa, presentada por el actual presidente, incluye dos temas que fueron demorados o rechazados en iniciativas previamente presentadas por ciudadanos: minería, por un lado y extracción petrolera en el Parque Nacional Yasuní, por otro.

La primera iniciativa de consulta popular votada en nuestro rango temporal se refirió a territorio y límites a nivel local. No contó con el dictamen de la Corte Constitucional y fue activada por el presidente Correa. Fue de jurisdicción cantonal, referente a qué provincia pertenecía el cantón La Concordia. En 1978, la Comisión de Límites Internos de la República había establecido que el cantón pertenecía a la provincia de Pichincha (El Comercio, 2011); sin embargo, las competencias de educación eran asumidas por el gobierno provincial de Esmeraldas. En 2007, se crea la provincia de Santo Domingo de los Tsáchilas, con lo que la pugna pasa a ser entre esta nueva provincia y Esmeraldas. Con la consulta, los habitantes finalmente decidieron pertenecer a Santo Domingo de los Tsáchilas. Como se puede ver, la consulta implicó la solución a un conflicto de larga data que solamente encontró solución con la intervención del presidente de la República, ya que el tema era de su exclusivo uso en consultas populares.

La segunda iniciativa votada incluía varios temas. El más controversial se refería a la restructuración de la función judicial. Esto podría significar una falta de independencia de funciones, considerando que la iniciativa surgió en el Ejecutivo y que implicaba un nombramiento de un Consejo de la Judicatura realizado por el presidente. Otra pregunta proponía la prohibición a accionistas de entidades financieras de ser propietarios de medios de comunicación; creó controversia ya que muchos periodistas críticos al régimen de Correa trabajaban en el canal Teleamazonas, cuyo propietario era Fidel Egas, dueño del banco más grande de Ecuador, Banco Pichincha. 
Entre los otros temas, uno contaba con gran popularidad entre los defensores de animales, ya que versaba sobre la prohibición de espectáculos que incluyan la muerte de un animal como corridas de toros, peleas de gallos, etc. Esta pregunta generó discusión en la ciudad de Quito, en donde cada año se lleva a cabo la Feria Taurina Jesús del Gran Poder desde 1960. En 2010, la Defensoría del Pueblo presentó una acción de protección para prohibir la entrada de niños menores de 12 años a corridas de toros y previamente se había aplicado esta prohibición como medida cautelar (El Comercio, 2009). Por lo tanto, era un tema con movilización antecedente.

La tercera iniciativa votada fue relacionada a territorio y adscripción de tierras comunitarias a la parroquia de Caspigasí del Carmen. Es la primera iniciativa ciudadana que llegó a votarse y con esta experiencia, una pregunta referida a territorio es incluida en la cuarta iniciativa votada, esta vez patrocinada por el presidente Correa.

La quinta iniciativa no llegó a votarse por desistimiento del ciudadano activante. Ha sido la primera y única vez que esto ha ocurrido. Se refería a costos de pasajes de transporte público.

La sexta iniciativa se refirió a prohibiciones a empleados públicos y fue activada por el entonces presidente Correa. La pregunta propuesta fue: “¿Está usted de acuerdo en que, para desempeñar una dignidad de elección popular o para ser servidor público, se establezca como prohibición tener bienes o capitales, de cualquier naturaleza, en paraísos fiscales?”. Esta pregunta estaba direccionada al mayor opositor al oficialismo en las elecciones presidenciales a llevarse a cabo en 2017, Guillermo Lasso, de quien se decía, tenía bienes en paraísos fiscales.

La séptima iniciativa votada fue activada por el presidente Lenín Moreno; contenía varios temas e incluía preguntas de referéndum y de consulta popular: reformas a la Constitución respecto a corrupción, reelección de autoridades, cesación de funciones de los miembros del Consejo de Participación Ciudadana y Control Social²; delitos sexuales contra menores; prohibición de

2 De acuerdo a la Constitución del Ecuador, existen 5 funciones: legislativa; ejecutiva; de justicia y justicia indígena; transparencia y control social; $\mathrm{y}$, electoral. 
hacer minería en áreas protegidas, zonas intangibles y centros urbanos; derogación de la Ley de Plusvalía; extracción de petróleo en el Parque Nacional Yasuní.

La octava iniciativa que se convirtió en consulta popular fue propuesta por ciudadanos en 2012 y llegó a votarse en 2019. Se refiere a minería en la zona de Quimsacocha y la explicaremos posteriormente.

Es importante señalar que, de nuestra muestra de 34 iniciativas de consulta popular, seis de ellas se refirieron o incluyeron preguntas respecto a actividades petroleras o mineras, tornándolo un tema de interés por parte de la ciudadanía (es el tema que más se repite). En Ecuador, las iniciativas respecto a este tema no solo provienen de comunidades indígenas y campesinas, sino también de colectivos y ciudadanos. La preocupación por la protección del ambiente o la politización del extractivismo es creciente en Ecuador.

Como observamos en la primera tabla, la explotación en el Parque Nacional Yasuní era el tema de cuatro iniciativas. Tres de ellas fueron iniciadas por la ciudadanía y una por el presidente de la República, todas ellas, con alcance nacional. Ninguna de las tres primeras cumplió con el requisito de legitimidad democrática, y la del presidente no obtuvo dictamen de la Corte Constitucional dentro del plazo determinado. Sin embargo, solo la consulta del presidente llegó a votarse.

\section{c. Consultas sobre extracción petrolera en el Parque Nacional Ya- suní en diferentes momentos}

El Parque Nacional Yasuní se considera uno de los lugares más biodiversos del planeta, siendo conocido como un hotspot biológico. También es el hogar de pueblos indígenas Huaorani no contactados Tagaeri y Taromenane. El Bloque ITT (Ishpingo Tambococha Tiputini) está localizado en este parque, y una parte del mismo está en la zona declarada intangible para proteger la biodiversidad y la vida de los pueblos no contactados.

El plan de gobierno de Rafael Correa llegó con la iniciativa Yasuní ITT, que fue incluida en el Plan Nacional de Desarrollo 2007. Consistía en el compromiso de Ecuador de mantener 846 barriles de crudo existentes en 
el bloque ITT, indefinidamente bajo tierra. A cambio, la comunidad internacional debía cooperar a través de donaciones de al menos la mitad de las ganancias que provendrían de la explotación petrolera. La iniciativa pretendía colectar donaciones por $\$ 3.600$ millones de dólares en 13 años. Solamente alcanzó "USD \$13.3 millones en depósitos y \$116 millones en compromisos" (Mena, 2013), hasta agosto de 2013, cuando el presidente Correa la declaró finalizada a través de un mensaje televisado y anunció la explotación del bloque. Correa dijo que ésta solo afectaría el $0,0001 \%$ del territorio del Parque Nacional Yasuní y se realizaría con los más altos estándares ecológicos.

Tras el fin de la iniciativa Yasuní ITT, Julio César Trujillo con el colectivo YASunidos, presentaron una iniciativa de consulta popular en agosto de 2013. La pregunta decía “¿está usted de acuerdo en que el gobierno ecuatoriano mantenga el crudo ITT, conocido como bloque 43, indefinidamente bajo el subsuelo?" Los YASunidos organizaron la recolección de firmas con un despliegue de voluntarios a nivel nacional.

En septiembre de 2013, la Corte Constitucional emite la sentencia erga omnes en que modifica el orden de cumplimiento de los requisitos de las iniciativas de consulta popular.

El CNE requería 583.324 firmas de apoyo para que la iniciativa alcanzara legitimidad democrática. Se recolectaron más de 1'070.000 firmas, pero en su mayoría fueron declaradas no válidas. YASunidos denunció varias irregularidades en el proceso de verificación. Para 2014, el presidente del CNE oficialmente declaró que las firmas no eran válidas y que el requisito de legitimidad democrática no se había cumplido.

El 27 de septiembre de 2013 otra iniciativa de consulta popular referida al crudo del Yasuní se presentó por un ciudadano. La pregunta propuesta era: “¿Debe el Estado ecuatoriano mantener bajo el suelo el petróleo del bloque 43 (Ishpingo Tambococha Tiputini) por lo menos hasta el año 2030 y en sustitución productiva iniciar un programa de reforestación de por lo menos doscientas mil hectáreas?". El proceso no fue completado por el activante.

El 11 de junio de 2014, una iniciativa de otro grupo de ciudadanos y cabezas de gobiernos locales llamado Amazonía Vive, fue presentada. In- 
cluía la pregunta “¿Apoya al presidente constitucional de la República, Econ. Rafael Correa Delgado, en su propuesta para la explotación de petróleo en un área no mayor al 1 por mil del Parque Nacional Yasuní y que el producto del petróleo que se extraiga del bloque 43 (Campo ITT) se destine a la lucha contra la pobreza, la protección ecológica del país, el financiamiento de los planes de vida de las comunidades ancestrales y la dotación de servicios básicos?" La legitimidad democrática no se cumplió y la consulta popular no se llevó a cabo.

En octubre de 2017 y con un nuevo presidente en ejercicio, Lenín Moreno, se presenta una iniciativa de consulta popular a la Corte Constitucional. Entre otros temas de inestable popularidad en el gobierno de Correa, se presentó la pregunta: “¿Está usted de acuerdo en incrementar la zona intangible en al menos 50.000 hectáreas y reducir el área de explotación petrolera autorizada por la Asamblea Nacional en el Parque Nacional Yasuní de 1.030 hectáreas a 300 hectáreas?”. La Corte Constitucional no dio su dictamen y con base en la anterior consulta iniciada por el presidente Correa y votada sin dictamen de la Corte Constitucional, se procedió a convocar la votación mediante decreto.

Como podemos ver, estas cuatro iniciativas fueron presentadas respecto a extracción de crudo en el Parque Nacional Yasuní. Una de ellas, activada por el presidente de la República y las otras, por la ciudadanía. Ninguna de ellas obtuvo dictamen de constitucionalidad, aunque la de Moreno procedió con base en el incumplimiento del plazo de pronunciamiento de la Corte Constitucional.

La presentación de tres iniciativas respecto a este tema en fechas cercanas a cuando Correa dio por terminado el proyecto Yasuní ITT, nos muestra que era un asunto de gran interés público y que se quedó en el imaginario de las personas por un largo tiempo. El tema fue traído estratégicamente a colación nuevamente por Lenín Moreno junto a asuntos como la Ley de Plusvalía, que generó protestas en sectores medios y altos del Ecuador; y para modificar la cuarta función del Estado: la de transparencia y control social, cuya labor tenía bajos niveles de popularidad (Beltrán, 2017). 


\section{d. Cumplimiento de requisitos legales}

Nuestra principal hipótesis alternativa decía que las iniciativas de consulta popular que llegan a concretarse son aquellas que cumplen con los requisitos legales establecidos, lo que sería una consecuencia lógica en un Estado de Derecho. En nuestra muestra aquellas que cumplieron los requisitos legales sí coinciden con las que se votaron; sin embargo, notamos un detalle: en el caso de no haber pronunciamiento de la Corte Constitucional dentro de los veinte días de plazo, se procede a realizar la consulta popular solo para las iniciativas activadas por el presidente. El caso de la consulta de minería en Quimsacocha tuvo que esperar cuatro años desde que se cumplió el requisito de legitimidad democrática, hasta que la consulta se celebró efectivamente.

Hasta enero de 2019, la consulta de Quimsacocha era la gran excepción de iniciativas que habían cumplido con todos los requisitos legales y que no habían sido votadas. A pesar de haber llegado a buen término y que Girón se pronunció respecto al tema, el largo proceso da cuenta de un caso diferente y único dentro de la muestra de iniciativas presentadas, que a la vez se sirvió de resultados de la consulta anterior respecto a la modificación de la función de transparencia y control social. Todas estas características nos indican que esta consulta merece una investigación específica.

De acuerdo a la Tabla 1, en muchos casos se pone a disposición los formularios de recolección de firmas, pero no son retirados, o no se completa la recolección. En la consulta del Yasuní, la falta de legitimidad democrática ha sido cuestionada, ya que la revisión de requisitos no siguió los protocolos establecidos, de acuerdo a los testimonios del colectivo YASunidos (YASunidos, 2016)

Para el caso de la consulta de transporte en Guayaquil, no se establece ningún tipo de sanción a quienes han pasado el proceso correspondiente de manera exitosa, pero deciden no llevar a cabo la consulta.

\section{e. Consulta sobre minería en Quimsacocha}

El proyecto Quimsacocha se encuentra en la provincia de Azuay, al sur de la sierra ecuatoriana. La concesión de la misma para su exploración y 
explotación fue otorgada a la empresa canadiense Iamgold (Observatorio de Conflictos Mineros, 2018) cuya participación fue posteriormente adquirida por la empresa INV Metals, también canadiense.

De acuerdo al Observatorio de Conflictos Mineros para América Latina, el proyecto Quimsacocha, actualmente conocido como Loma Larga, se encuentra en fase de exploración. El Ministerio de Ambiente dice que 3217 hectáreas fueron recuperadas de la concesión inicial que consistía en 12.000 hectáreas (Ministerio de Ambiente, 2018). Esta recuperación se realizó para declarar a este espacio como un área nacional de recreación.

En 2011, los habitantes de Tarqui y Victoria del Portete organizaron una consulta autónoma y autoconvocada, para preguntar a sus habitantes respecto a si aceptan o no actividades mineras en Quimsacocha. 1073 electores participaron en el proceso. $92,38 \%$ se pronunciaron contra de la minería en el área (El Universo, 2011). Este proceso fue públicamente descalificado por el presidente Correa y sus resultados no tuvieron carácter vinculante.

Tras ello, habitantes del cantón Girón, a través de la Federación de Organizaciones Indígenas y Campesinas del Azuay, decidieron auspiciar una iniciativa de consulta popular el 03 de marzo de 2012. La pregunta en la iniciativa establecía: “¿Está usted de acuerdo con que se realicen actividades mineras en los páramos o fuentes de agua del Sistema Hidrológico Quimsacocha?". La recolección de firmas inició en enero de 2015, cuando fueron entregados los formularios, siendo validadas en julio del mismo año. Los archivos del CNE señalan que la iniciativa pasó a la Corte Constitucional y estuvo represada hasta finales de 2018, tras un cambio de gobierno, una consulta que cambió el Consejo de Participación Ciudadana y Control Social y con eso, a las autoridades del CNE y a los jueces de la Corte Constitucional. Finalmente, en 2019 la Corte Constitucional señaló que su plazo de pronunciamiento había prescrito por lo que archivó la causa. Con ello, el nuevo CNE llevó a cabo la consulta popular, que se votó en marzo de 2019.

La consulta popular de Quimsacocha demuestra que el cumplimiento de los requisitos legales no implica una inmediata celebración de la consulta popular y que la aplicación del plazo de veinte días para el pronunciamiento 
de la Corte Constitucional se da inmediatamente si quien propone la consulta es el presidente de la República, mientras que, en este único caso de consulta de iniciativa ciudadana, tardó cuatro años en aplicarse.

\section{Resultados e implicaciones}

Demostramos que las consultas activadas o auspiciadas por el ejecutivo llegan a la instancia de consulta popular.

También hemos encontrado que el tema que más se repite en consultas de iniciativa ciudadana es la explotación de recursos no renovables, siendo la consulta de Quimsacocha, la única que se ha votado. Otra oportunidad en que una pregunta sobre este tema ha llegado a consulta popular ha sido propuesta por el Ejecutivo, esta vez durante la gestión de Lenin Moreno.

Observamos un doble estándar de aplicación del plazo de veinte días de pronunciamiento de la Corte Constitucional, en el período seleccionado. Llama la atención que, con el dictamen de la Corte Constitucional que cambia el orden de cumplimiento de requisitos, el CNE rechaza algunas iniciativas, declarando su inconstitucionalidad, a pesar de que este no es su trabajo.

No podemos establecer una relación fuerte respecto al momento de llevar a cabo consultas populares sobre determinados temas. Iniciativas de consulta sobre explotación petrolera en el Yasuní mostraron que era un asunto de gran interés ciudadano, cuando se declaró el fin del proyecto en agosto de 2013. El uso de este tema dentro de la consulta de Lenin Moreno en 2017 y votada en 2018, muestra que se incluyeron temas con gran popularidad previa, junto a otros que podrían resultar más controversiales.

Encontramos dos iniciativas de jurisdicción nacional, ambas activadas por el presidente de ese momento -Correa en 2011 y Moreno en 2017-que incluían temas que implicaban una intervención directa en otras funciones del Estado, y fueron combinadas con temas con antecedentes de movilización. En 2011, Correa combinó en su consulta preguntas sobre prohibición de espectáculos que incluyan la muerte de un animal con preguntas respecto a la transformación de la función judicial. En 2017, Moreno combinó en su iniciativa una pregunta sobre extracción de petróleo en el Yasuní y otra de 
minería, con transformaciones en la función de transparencia y control social.

Si tenemos en cuenta que la consulta de 2011 tuvo tantos temas como la de 2017, celebrada en 2018, podríamos concluir que, en Ecuador las consultas populares son mecanismos utilizados por el ejecutivo de turno para incluir temas controversiales en la agenda pública, con beneficio de los otros temas con histórica -aunque reciente- popularidad.

Para algunos sectores, la consulta popular auspiciada por el presidente en 2011, "constituía un episodio más de la incesante búsqueda de relegitimidad del liderazgo presidencial -la "campaña permanente"- propia de un estilo populista de gestión” (Ramírez, 2014, pág. 243). Podríamos decir lo mismo de la consulta de Moreno iniciada en 2017 sumado a una ruptura con su antecesor. Es decir, hay un uso específico desde el Ejecutivo respecto a las consultas populares.

\section{A manera de conclusión}

Podemos observar que las iniciativas que llegan a ser votadas se relacionan con quién las auspicia: son las iniciadas por el Poder Ejecutivo las que llegan a ser consulta popular. La combinación de temas en consultas populares y nuestra conclusión refuerza las advertencias de Welp (2016) y Lissidini (2015) que señalan que la democracia directa, activada desde arriba podría ser un mecanismo para legitimar o apoyar decisiones del Ejecutivo, y podría ir en desmedro de la división de funciones.

La necesidad de fortalecer la democracia y sus instituciones que se originó desde su retorno en las últimas décadas del siglo XX y persistió en la década de inestabilidad política que sufrió Ecuador entre 1997 y 2007, parecería estar formalmente cubierta, ya que las instituciones y los mecanismos han sido creados y están disponibles en cuerpos legales para diferentes actores. Sin embargo, el uso de consultas populares respecto a temas que interesan a la ciudadanía, y sobre los que la gente desea pronunciarse es de difícil acceso. Las instituciones no se pronuncian a tiempo o existe un abandono de las iniciativas ciudadanas al momento de cumplir el requisito de legitimidad democrática. Así, esta conclusión reafirma lo expresado por Altman (2010). 
Hemos visto que muchos casos no se completa la recolección de firmas o ni siquiera se retira los formularios. Debería haber un seguimiento a los actores, para conocer profundamente las razones de este desistimiento.

Finalmente, podemos observar que muchas consultas se realizan respecto a explotación de recursos naturales no renovables, es decir, existe un deseo ciudadano de participación a través de MDDs para pronunciarse ante al extractivismo. A pesar del inicial apoyo que pudo tener la participación ciudadana respecto a estos temas, en la práctica, el uso de consultas populares sobre extractivismo parece ser un asunto reservado para ser activado desde el Ejecutivo y de difícil acceso para la ciudadanía. Sería prudente que exista formación o direccionamiento desde las instituciones respecto a la activación de consultas populares ciudadanas, para que así el cumplimiento de requisitos legales se torne factible, sin que esto implique un abuso del uso de estos mecanismos que vaya en desmedro de la democracia representativa. 


\section{Bibliografía}

Altman, D. (2010). "Plebiscitos, referendos e iniciativas populares en América Latina: ¿mecanismos de control político o políticamente controlados?" Perfiles Latinoamericanos(35), 9-34.

Avritzer, L. (2012). "Democracy beyond aggregation: the participatory dimension of public deliberation". Journal of Public Deliberation, 8(2), $1-22$.

Beltrán, J. (2017). ¿De dónde vienen las preguntas de la consulta popular? Obtenido de GK: https://gk.city/2017/10/10/preguntas-consulta-popular-ecuador-2017/

El Comercio. (2009). Los niños no podrán ver las corridas de toros. Obtenido de https://www.elcomercio.com/actualidad/ninos-no-podran-ver-corrida.html

El Comercio. (2011). La Concordia: un territorio que se disputan entre Esmeraldas y Santo Domingo. Obtenido de https://www.elcomercio. com/actualidad/ecuador/concordia-territorio-disputan-esmeraldas-y.html

El Universo. (2011). El pueblo de Quimsacocha vota en contra de la minería. Obtenido de https://www.eluniverso.com/2011/10/02/1/1355/ poblacion-quimsacocha-contra-mineria.html

Larrea, C. (2007). Iniciativa Yasuní ITT. Obtenido de https://opsur. files.wordpress.com/2009/07/yasuni-itt.pdf

Lissidini, A. (2015). "Democracia directa en América Latina: avances, contradicciones y desafíos". En A. Minnaert, \& G. (. Endara, Democracia Participativa e Izquierdas Logros, Contradicciones y Desafios (págs. 120-189). Quito: Fredich Ebert Stiftung.

Lissidini, A., Welp, Y., \& Zovatto, D. (2014). "Prefacio: La política en movimiento". En A. Lissidini, Y. Welp, \& D. Zovatto, Democracias en Movimiento: Mecanismos de Democracia Directa y Participativa en América Latina (págs. 1-12). México DF: Universidad Autónoma de México. 
Mena, P. (2013). ¿Por qué fracasó el proyecto ambiental del Yasuní en Ecuador? Obtenido de BBC: http://www.bbc.com/mundo/mundo/noticias/2013/08/130816_ecuador_yasuni_causas_fracaso_lps

Ministerio de Ambiente. (2018). Área Nacional de Recreación Quimsacocha. Obtenido de http://areasprotegidas.ambiente.gob.ec/es/areas-protegidas $/ \% \mathrm{C} 3 \% \mathrm{~A} 1$ rea-nacional-de-recreaci $\% \mathrm{C} 3 \% \mathrm{~B} 3 \mathrm{n}$-quimsacocha

Morales, J. (2008). “Los nuevos horizontes de la participación”. En R. Ávila, La Constitución de 2008 en el contexto andino (págs. 155-200). Quito: Ministerio de Justicia y Derechos Humanos.

Observatorio de Conflictos Mineros. (2018). Proyecto Quimsacocha. Obtenido de https://mapa.conflictosmineros.net/ocmal_db-v2/proyecto/ view/411

Ramírez, F. (2014). "La democracia directa en Ecuador posconstitucional”. En A. Lissidini, Y. Welp, \& D. Zovatto, Mecanismos de Democracia Directa y Participación en América Latina (págs. 231-274). México DF: Universidad Nacional Autónoma de México.

Welp, Y. (2016). "El referéndum ante la crisis de legitimidad: ¿solución o síntoma del problema? Un análisis de América Latina en el siglo XXI" . En F. Tuesta Soldevilla, Partidos políticos y elecciones. Representación politica en América Latina (págs. 145-159). Lima: JNE.

YASunidos. (2016). Cronología. Obtenido de http://sitio.yasunidos. org/es/yasunidos/cronologia-de-hechos-html

Zovatto, D. (2014). "Las instituciones de la democracia directa". En A. Lissidini, Y. Welp, \& D. Zovatto, Democracias en Movimiento: mecanismos de Democracia Directa y Participativa en América Latina (págs. 1370). México DF: Universidad Nacional Autónoma de México.

\section{Sentencias}

Corte Constitucional del Ecuador. 001-13-DCP-CC de 25 de septiembre de 2013. 